\title{
Exploring the Bond between Man and Nature in Amitav Ghosh's The Hungry Tide
}

\author{
Swagatalakshmi Basu
}

Department of English, SACT of Swarnamoyee Jogendranath Mahavidyalaya. Purba Medinipur, West Bengal, India.

\begin{abstract}
The study of the inexplicable bond between the nature and human is analyzed in literature by new terminology - "Eco criticism". Eco-critical theory emphasizes the significance of not just the human beings but also the physical environment as represented in literature. In $21^{\text {st }}$ century the theory of eco-criticism displays a growing awareness of environmental issues. At present, environmental degradation has emerged as a major global concern for humanity. Global warming coupled with carbon emission is one of the reasons for environmental degradation. If the adverse impact of ecological degradation is not checked immediately our modern civilization will collapsed. Jnanpith award winner Amitav Ghosh in his novel The Hungry Tide writes about nature, people and environmental problems along with the climate change in the tidal area of the Sundarbans. That's why I have selected The Hungry Tide as my case study to explore the bond between man and nature. This paper will show how nature is being affected by human activities due to lack of awareness about the conservation of nature. How nature and human beings have been depicted in The Hungry Tide_- as protector or as destroyer to each other? At the same time, I have attempted to point out what is the role of human being towards nature in maintaining harmony between man and nature, survival of humanity and conservation of nature in the era of globalization.
\end{abstract}

Keywords-Ecocriticism, environmental issues, ecological degradation, humanity, conservation.

\section{INTRODUCTION}

Man has been interacting with the nature and advancing over the years. Evolutionary process made man more conciliatory and compatible with the nature as time progresses man intervenes into the nature more and more for survival. The question of survival was prime at the initial stage. Every action has equal and opposite reaction, with increased intervention, the nature too intervene in opposite direction. As a result contradiction between man and nature intensifies. As this contradiction sharpens over time man progresses forms, groups and societies begin to live collectively. Modern man, influenced by the capitalist market forces, destroys nature with the technology, modern living style on one hand screams out slogans to save nature on the other. In that case Darwin's theory of evolution, theory of "Survival of the strongest" works well. Due to modern technology environmental degradation, being the most terrific challenge of the recent times. In this time the relation between man and physical environment has been a part of literature: named
Ecocriticism. Inclusion of various issues related to environment and ecology in literary works, helpful in raising environmental consciousness among common people. The terms Ecocriticism, environmental ethics and environmental humanities - should be popularized to raise climate change awareness among commoners.

\section{ECOCRITICISM}

The term "Ecocriticism" first appeared in Eco-critic William Ruckert's essay "Literature and Ecology: An Experiment in Ecocriticism" in 1978. Ecocriticism advocates sustainable development for a better future of mankind in general. Ecocriticism considers that ethical orientation of the text facilitates human accountability. Eco-critical theory emphasizes the significance of not just the human but also the non-human in literature. In $21^{\text {st }}$ century the theory of ecocriticism displays a growing awareness of environmental issues. This theoretical approach uses literature as a pre text 
to study environmental issues and evaluates relevant texts according to their capacity to articulate ecological contexts. Eco-criticism expands the notion of 'the world' to include the entire ecosphere. Ecology is concerned with inexplicable relationship between living organisms and natural environment. All organisms have their right to survive in their own way. The environmental issue related literary works beautifully deal with human and nature interconnection as the key note of literature and theoretical discourse. Jnanpith Award winner Amitav Ghosh's most of the fictions are reflection of his concern about environment and well being of all human-beings.

\section{CO-EXISTENCE OF HUMAN AND NON- HUMAN}

Great Indian Writer Amitav Ghosh's The Hungry Tide is the best example to represent the bond between man and nature. Through this fiction he combines the art of nature and the struggle between human and non-human, both forming an integral part of nature. People, habits and dolphins of Sundarbans represent the entire ecological systems of the archipelago. The relationship between disciplines such as literature and environmental studies have been harmoniously reintegrated by Ghosh so as to explore possibilities of ethical evaluation of human responsibility towards our environment of which we too are an integral part. The Hungry Tide_is a presentation of bioregion, The Sundarbans with its endangered flora and fauna along with marginalised people who struggle to constitute a niche against all the oddities of the biome which is known as "tide country". According to Ghosh's description, "the number in the thousands, these islands some are immense and some have tasted through recorded history, while others were washed into being just a year or two ago..." in giving description of the shifting nature of the Sundarbans, a vast mangrove forest on the coast of India and Bangladesh, the text uncovers several issues related to life and existence on this delta with its diverse ecosystem in which both man animal and other beings strive for their survival. From the point of non human creatures of which the most powerful of the species the tiger has to conflict with man, the ever depleting richness of the biodiversity due to salinity sounding the death knell of several rare species and yet the ecosystem is home the Gangetic and Irrawaddy dolphins crocodiles with other fauna and flora at the point of extinction. The tides reach several miles in land and everyday thousands of mangroves disappear and re-emerge hours later. The consideration of human themselves as the most significant entity of the universe is considered to be the root cause of harm done to nature due to human actions. There are set of non human characters present in novel; sundaritrees, terrific Royal Bengal tiger, treacherous crocodile Orcella the crab dolphins - all these creatures represent the non anthropocentric voice in the novel against human counterparts contributing to our realization that nature is incomplete with human beings. Through the female protagonist Piyali Roy's protest against the killing of tiger, the Writer wants to tell that non human exists in the nature with a right to their very existence.

\section{ENVIRONMENTAL ISSUES AND CONSERVATION}

Human beings' superiority over nature gets vanished when he encounters the nature in its horrific form, and the realization of the fragility of his life on earth occurs to his mind. It is proved in novel when Kanai suddenly encounters the fierce tiger and when Piya, Fokir caught in the cyclone. In the episode of the tiger which is referred as 'the horror' in the novel the invasion of the predator into the human habits are consider as a punishable crime but destructing other species and killing them is not considered as serious crime by many people. The Hungry Tide poses a status of Nashequilibrium between survival of humanity and conservation of nature. The inhabitants of Sundarbans pose a threat to the sensitive Ecoregion, whereas the treacherous waves pose a threat to the islanders. The tide in this area is shaping the land and uprooting anything permanent. Terrible tide snatches the lives of people of this delta. Writer has beautifully portrayed the poor condition of Moyna when she loses her husband, Fokir, due to tide and cyclone. Fisherman Fokir and marine biologist Piya both are very much close to nature but their approaches to nature were different to the conservation issue. Tides of Sundarbans, tiger and crocodiles have a cause of concern as well as the climax point of the novel The Hungry Tide. It is a notable point here that the inhabitants of Sundarbans who are getting their lives against nature in order to get a livelihood are very poor and marginalized people. One of the important issues of this novel is the plight between refugees and the government who ordered to leave them the island where they lived to preserve the land and environment. They have to depend on their immediate nature to survive. They lose their lives due to attack of wild animal. People like Fokir, Horen, Kusum, are always placed on the margins with no choices at all. When the lives and needs of these dispossessed and poor people are 
taken care of, the stress will be reduced because of poverty, marginalization of people and environmental degradation accelerates on one another. The writer tries to show how human life's incident revolves with the nature. In The Hungry Tide Piyali Roy found difficulties as well as happiness when she visited Sundarban for her research of Irrawaddy dolphins. She hired a guide and a guard from forest department, but she was neither satisfied from guide nor from guard. She found difficulties because they had no knowledge of the water animals and she was not protected by them. The happiness came in her life when she met Fokir. He was not educated but had knowledge about dolphins and the area which is safe for human beings. Piya was happy as Fokir saved her life from drowning into salty water at the time of sea storm. But Happiness turned into agony when Fokir died in the process of saving her life in untimely storm. The writer has showed how happiness and agony revolves just like the climate change of Nature. Here the writer points out the deep rooted connection between human beings and nature.

\section{MYTH AS A PROTECTOR}

Ghosh beautifully describes the nature through these words: "It was late November and the weather was crisp and cool with a gentle breeze and honeyed sunlight". (16-170). At the same time through kanai's observation writer mentions the ignorance of common people towards nature, people are very busy in their own work. They have no time to enjoy the beauty of nature. But the writer has showed the myth around nature. The Hungry Tide contains the myth of Bon Bibi who is known as Goddess of forest, she saves them from tiger in the forest, which inhabitants of Sundarban considers the rule of their life. Complicated topography of Sundarban makes leading life against all the oddities of the biome. Here nature is divided between its two entities: human and non human. There should always a perfect balance to be maintained between these two parts for survival. The myth which beholds the islanders to enter onto domain of beast can be considered pro-naturalistic. Ecology, nature and myths are like motivators which lead to unstated basic convictions to sustain human efforts at ecological responsibility, just similar to the myth of Bon Bibi which ensures protection on either side through creating a kind of fear. When Nirmal is informed of the imaginary border between the realms of BonBibi and the realm of Dokhin Roy, he says: "I realized with a sense of shock that this chimerical line was, to her and to Horen as real as a barbed wire fence might be to me".
The writer mentions Indian culture, people worship nature in the form plants and animals. They worship them as a spiritual spirit or mythological figure. Nature and culture are interrelated.

\section{CONCLUSION}

Amitav Ghosh reveals various aspects of nature to link between human life and nature. The Hungry Tide correlates the nature and human and believes that any human action which interrupt the elements of nature, will eventually lead to the destruction of life. Man's existence and development everything is possible due to his relation with nature. Man's bonding with nature will be perfect harmony as long as he realizes the fact every form of his life and needs are fulfilled by Nature. Every Species contributes to the completeness of nature and has a right to live on earth but the anthropocentric attitude of man caused extreme domination upon nature without realizing that destruction of nature is nothing but destruction of mankind itself. Ghosh's text is source of awareness and sensitizing the readers to the unique mangrove forests of the world. He suggests a different, nonprogrammatic response to climate change: this fiction is part of such refined climate fiction which weaves history and current planetary crisis together and validates myths as a shaping tool of an environment aware unconscious and a comfort corner, especially for the indigenous communities stuck in an existential crisis. Set in ecologically and geographically dynamic and sensitive archipelago, the tide country of Sundarbans, unique narrative.

\section{REFERENCES}

[1] Ghosh, Amitav. The Hungry Tide. London: HarperCollins, 2004. Print.

[2] Nayar, Pramod K. "The Postcolonial Uncanny; The Politics of Dispossession in Amitav Ghosh's 'The Hungry Tide.”.JSTOR, www.jstor.org/stable/27917766.

[3] Rangarajan, Swarnalatha. Ecocriticism: Big Ideas and Practical Strategies, Scott Slovic (Ed.), Orient Blackswan, 2005.

[4] https://rowman.com/Action/SERIES/_/ETAP/EcocriticalTheory-and-Practice 